\title{
The Case for Energy Productivity: It's not Just Semantics
}

\section{Patrick Bean}

\section{Summary}

Ratios that link energy consumption, or its related emissions, to the economic value generated accommodate the differing progress on economic development of nations better than absolute measures. Policymakers are increasingly using indicators such as energy efficiency, intensity, and productivity to address the interrelated issues of economic development, energy security, and environmental sustainability.

Although setting formal targets in terms of energy intensity has helped to build consensus on several issues, policymakers have an opportunity to enroll even greater public support through the use of energy productivity.

Energy productivity and energy intensity may be reciprocals that share the same components and policy-relevant attributes. But energy productivity has important advantages - the differences between the two measures go beyond semantics. Productivity has a more positive connotation, is more intuitive, is aligned with efficiency, and portrays grander ambition. From a behavioral economics perspective, these traits can help frame policies that yield more meaningful improvements.

The mathematical representation of energy intensity makes comparisons of relative change across time and countries more difficult because of something we call the energy intensity illusion - the metric appears to converge towards a mean. Energy productivity's mathematical representation, on the other hand, avoids this illusion, providing additional insight and making it a more directly relevant measure of a country's economy, energy, and environmental performance. 


\section{About KAPSARC}

The King Abdullah Petroleum Studies and Research Center (KAPSARC) is an independent, non-profit research institution dedicated to researching energy economics, policy, technology, and the environment across all types of energy. KAPSARC's mandate is to advance the understanding of energy challenges and opportunities facing the world today and tomorrow, through unbiased, independent, and high-caliber research for the benefit of society. KAPSARC is located in Riyadh, Saudi Arabia.

\section{Legal notice}

(C) Copyright 2014 King Abdullah Petroleum Studies and Research Center (KAPSARC). No portion of this document may be reproduced or utilized without the proper attribution to KAPSARC. 


\section{Aligning policy agendas}

All nations face the challenges of economic competitiveness, availability of energy resources, and environmental sustainability - and the tradeoffs that inevitably arise between these and other factors at play. Does a nation have access to the affordable energy resources required to fuel its economic growth objectives or is its weak economic standing limiting its access to energy? Will its economic aspirations come at the expense of the environment or will environmental policies thwart economic competitiveness? These questions are faced by many nations, developed and developing alike.

Energy efficiency, energy intensity (and the closelyrelated carbon intensity), and energy productivity have been used by policymakers around the world in response to global climate change concerns. Intensity targets have been seen as more acceptable than absolute greenhouse gas emission limits because they allow for emissions to grow in absolute terms as economies develop, even as they fall in relative terms. Although most formal targets have been set in terms of energy intensity, and this has helped to build consensus on several issues, there are important reasons to believe that energy productivity provides a better way forward.

How can that be if energy productivity and energy intensity are merely reciprocals? The distinction between the two metrics may seem purely semantic at first, but we will explain the differences and their importance to analyzing performance and framing policy targets in this briefing.

The stakes are high. Energy is a key input to economic processes. However, energy consumption is also the largest source of greenhouse gas emissions. Consuming energy in the most economically efficient manner possible can reduce the growth trajectory of greenhouse gas emissions while enhancing economic competitiveness and relieving demand pressures on energy resources. The McKinsey Global Institute estimates that the implementation of energy productivity opportunities --such as retrofitting buildings, switching to hybridelectric cars, and other measures--could offset 80 percent of currently expected growth in global energy demand through 2030.

Energy productivity, a measure of economic output per unit of energy consumption, aligns more directly with economic, energy, and environmental policy agendas than energy intensity and other measures. Energy productivity is more intuitive, has a more positive connotation, influences behavioral responses differently, and is more informative than energy intensity. It may lead to more popular support for policies and greater understanding of relative performance and opportunities for improvement.

\section{Energy productivity, intensity, and efficiency}

At an economy-wide level, energy productivity is the amount of economic output--such as gross domestic product (GDP)-achieved per unit of energy consumption. General measures of productivity can be computed on an average or marginal basis, but energy productivity is normally calculated in average terms. As a metric, energy productivity provides insights into a country's economic competitiveness, environmental performance, and opportunities for improvement. As a concept, energy productivity can serve as the foundation for policy options that align economic, energy, and environmental considerations.

Energy intensity is the reciprocal: the amount of energy consumed per unit of economic output.

Both measures are used as broad indicators of a nation's energy efficiency. The United Nations Foundation, for example, defines energy efficiency 
improvements as the reciprocal of reduction in energy intensity (i.e. energy productivity). This casual usage as a synonym obscures a deeper truthenergy productivity and intensity are influenced by many factors in addition to the energy efficiency of underlying economic components and processes. These include the structure of a nation's economy, its climate, physical geography, resource endowments, and other factors.

The structure of a nation's economy, which is typically related to its stage of economic development, plays an important role. An economy that produces a greater share of its economic output from energy intensive sectors such as cement and steel exhibits lower energy productivity than an economy with higher value added sectors and little energy use, such as financial services and pharmaceuticals. Within the world's twenty largest economies, two distinct patterns of energy productivity dynamics are prevalent. Figure 1 illustrates the first. In developed economies, the expansion of the service sectors relative to manufacturing has led to rapid increases in GDP at the same time as energy consumption levels stabilized, with little tangible increase over time. Therefore, these countries have made large energy productivity gains, as seen by their crossing of multiple iso-energy-productivity lines. Countries within the same iso regions in the figure have similar energy productivities, even with disparate energy use and GDP levels.

By contrast, Figure 2 shows how developing and transition economies in the G-20 have seen their energy consumption increase rapidly, but with smaller relative gains in GDP as they undergo rapid industrialization. Their relative energy productivity

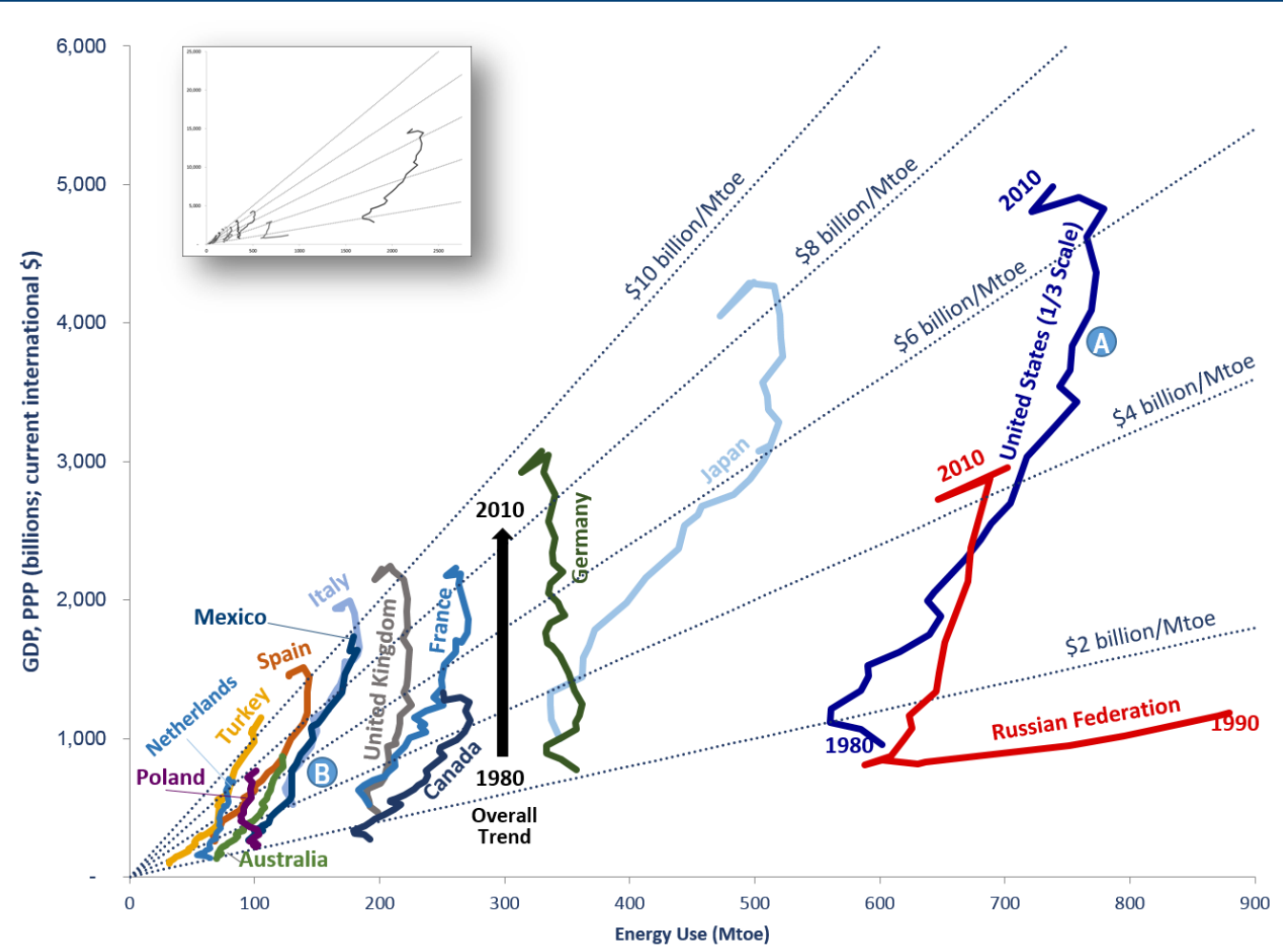

Figure 1: Similar trends of GDP expansion and energy use stabilization in large economies from 1980-2010. Iso lines for various energy productivity levels are included to show relative performance and changes over time. For example, points A and B show similar energy productivity at quite different levels of energy use and economic development. Note: Data for Russia and Poland begins in 1990. The United States is at one-third scale for easier comparison. Inset shows unadjusted values. Data source: World Bank 


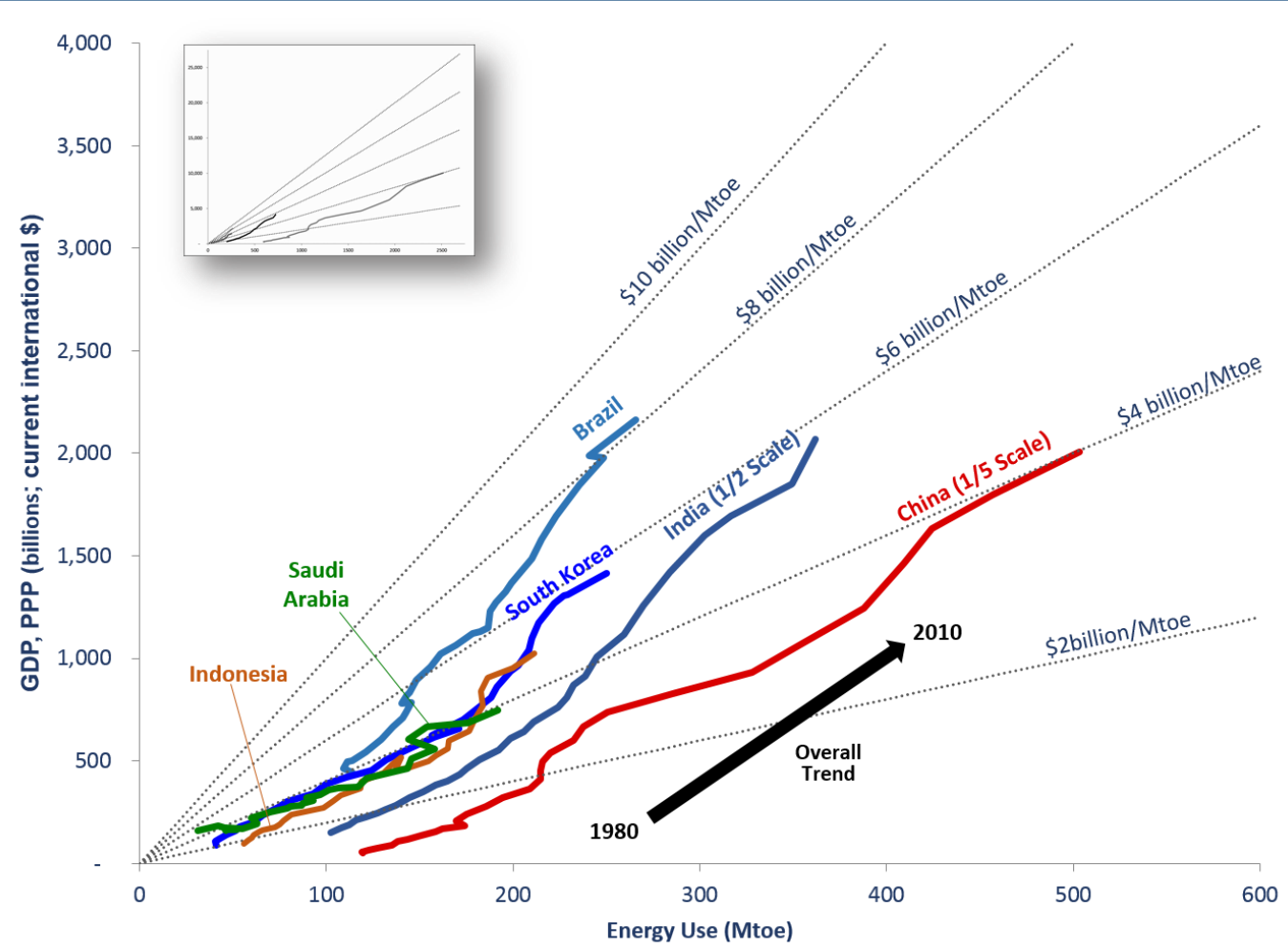

Figure 2: Similar trends of GDP expansion with rising energy consumption from 1980-2010. Iso lines for various energy productivity levels are included to show relative performance and changes over time. Note: Data for India and China are scaled at one-half and one-fifth scales, respectively, for easier comparison. Inset shows unadjusted values. Data source: World Bank

\begin{tabular}{|c|c|c|c|}
\hline Country & Target & Baseline & Target Year \\
\hline China & $15 \%$ energy intensity reduction & 2010 & 2015 \\
\hline Germany & $\begin{array}{l}2.1 \% \text { average annual energy productivity } \\
\text { improvement }\end{array}$ & 2008 & 2020 \\
\hline Indonesia & $1 \%$ energy intensity reduction per year & 2005 & 2025 \\
\hline Japan & $30 \%$ energy efficiency improvement & 2003 & 2030 \\
\hline Russia & $40 \%$ energy intensity reduction & 2007 & 2020 \\
\hline South Africa & $12 \%$ reduction in final energy consumption & Reference scenario & 2015 \\
\hline South Korea & $46 \%$ energy intensity reduction & 2007 & 2030 \\
\hline Turkey & $20 \%$ energy intensity reduction & 2008 & 2023 \\
\hline United Kingdom & $18 \%$ reduction in final energy consumption & Reference scenario & 2020 \\
\hline
\end{tabular}

Source: Adapted from European Commission reports, and ABB, 2013.

Table 1: A cross-section of energy performance targets. 
gains therefore lag those of developed nations over the last two decades.

Policymakers and analysts use energy metrics as proxies for economic, energy, and environmental performance, and to formulate policy targets. Targets can take the form of productivity improvements, absolute energy consumption reductions, or decreases in energy intensity. A crosssection of targets is provided in Table 1. Of the two metrics discussed here, energy intensity is used more often. Some nations have adopted energy and carbon intensity targets because they accommodate economic and emissions growth better than absolute targets. Most notably, three of the largest energy consumers in the world, China, India, and the United States have set intensity-based targets since the start of the millennium.

\section{Energy productivity advantages}

Although energy productivity and energy intensity are based on the same components, and share policyrelevant attributes, the two indicators evoke different responses. There are a number of facets to this, including:

\section{Positive connotation}

The differences begin with the connotations of the words themselves. 'Productivity' conveys a more positive quality than 'intensity'. This should not be dismissed as trivial - a positive quality can have potentially meaningful policy impact. Sher and McKenzie, in 2008, described how psychology and behavioral economics research has found that people react differently to choices based on how they are presented or framed.

\section{Behavioral differences}

Describing changes in energy productivity is also more intuitive and positively-framed than when expressed in terms of intensity. An improvement in energy productivity is represented by an increase in its value, whereas energy intensity improvements are represented by a decrease in value. This is not a new observation. Levin and Gaeth, in 1988, and Duchan, et al., in 1989, observed that objects and choices described in positive terms are preferentially adopted or have higher performance compared to identical alternatives described in negative terms. The difference between productivity and intensity is therefore not inconsequential.

\section{Aligning with efficiency}

Energy productivity is likely to resonate more widely amongst policymakers. Indicators like labor productivity (GDP or value added per hour worked) are already widely used by policy analysts. Notwithstanding the vernacular confusion noted earlier, energy productivity is closely aligned with the widely understood concept of energy efficiency, both being measures of output divided by input. Indeed, at a disaggregated, sector-specific or process -level basis, energy productivity becomes almost synonymous with energy efficiency.

\section{Instinctive understanding}

The general public and, most likely, policymakers also have a more instinctive understanding of currency than units of energy consumption. The different units used to express energy productivity and energy intensity have implications for framing policies and understanding relative performance. Energy productivity is measured in dollars of GDP per unit of energy, which is more readily understood given the well-established frame of reference for monetary values. By contrast, energy intensity is measured in energy consumption units (e.g. tons of oil equivalent, British thermal units, or joules) per unit of GDP. Although the same units are used in both measures, the primary unit for productivity is one that is more intuitive. 


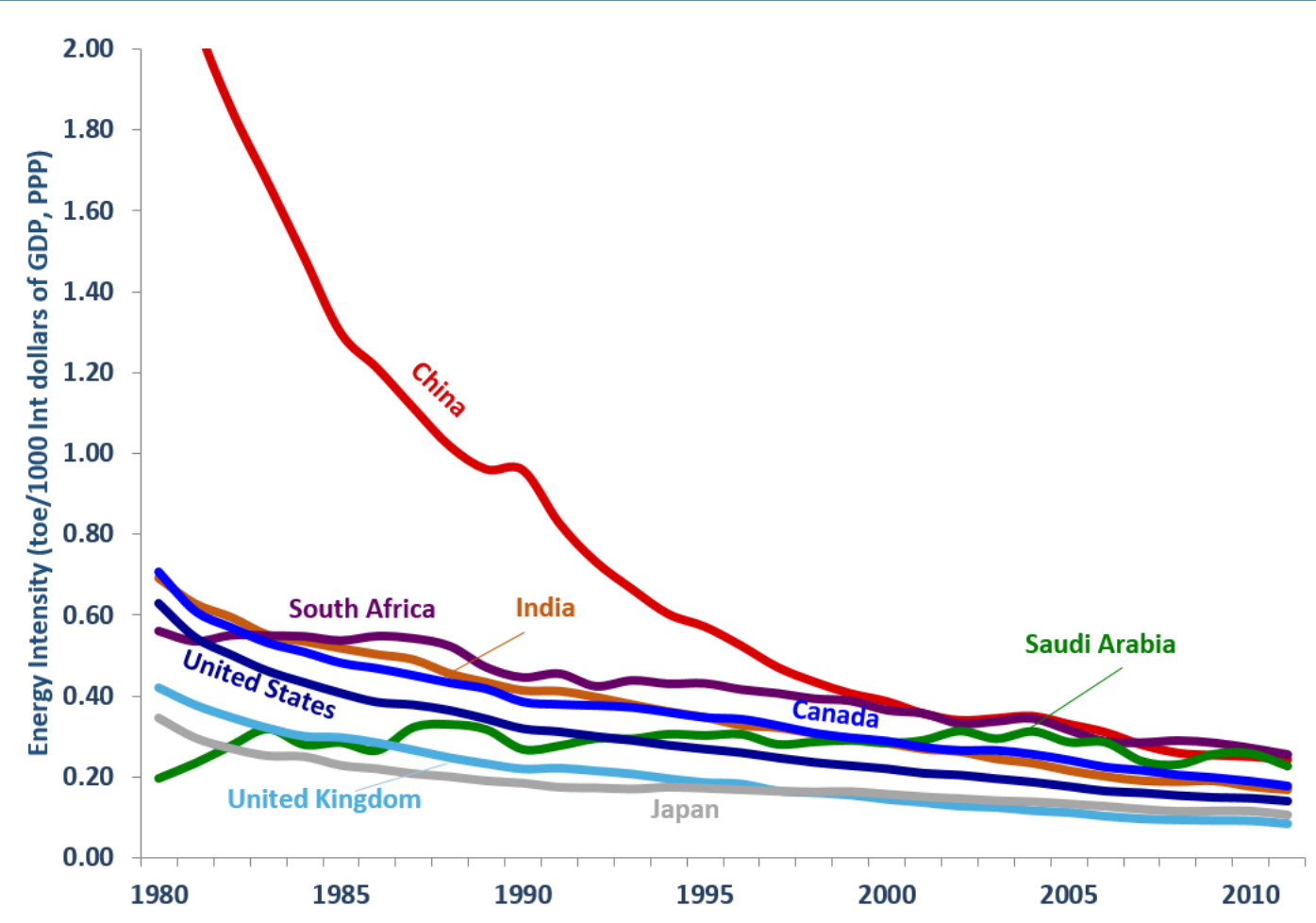

Figure 3: Changes in energy intensity for select countries, 1980-2011. Energy and GDP data source: World Bank.

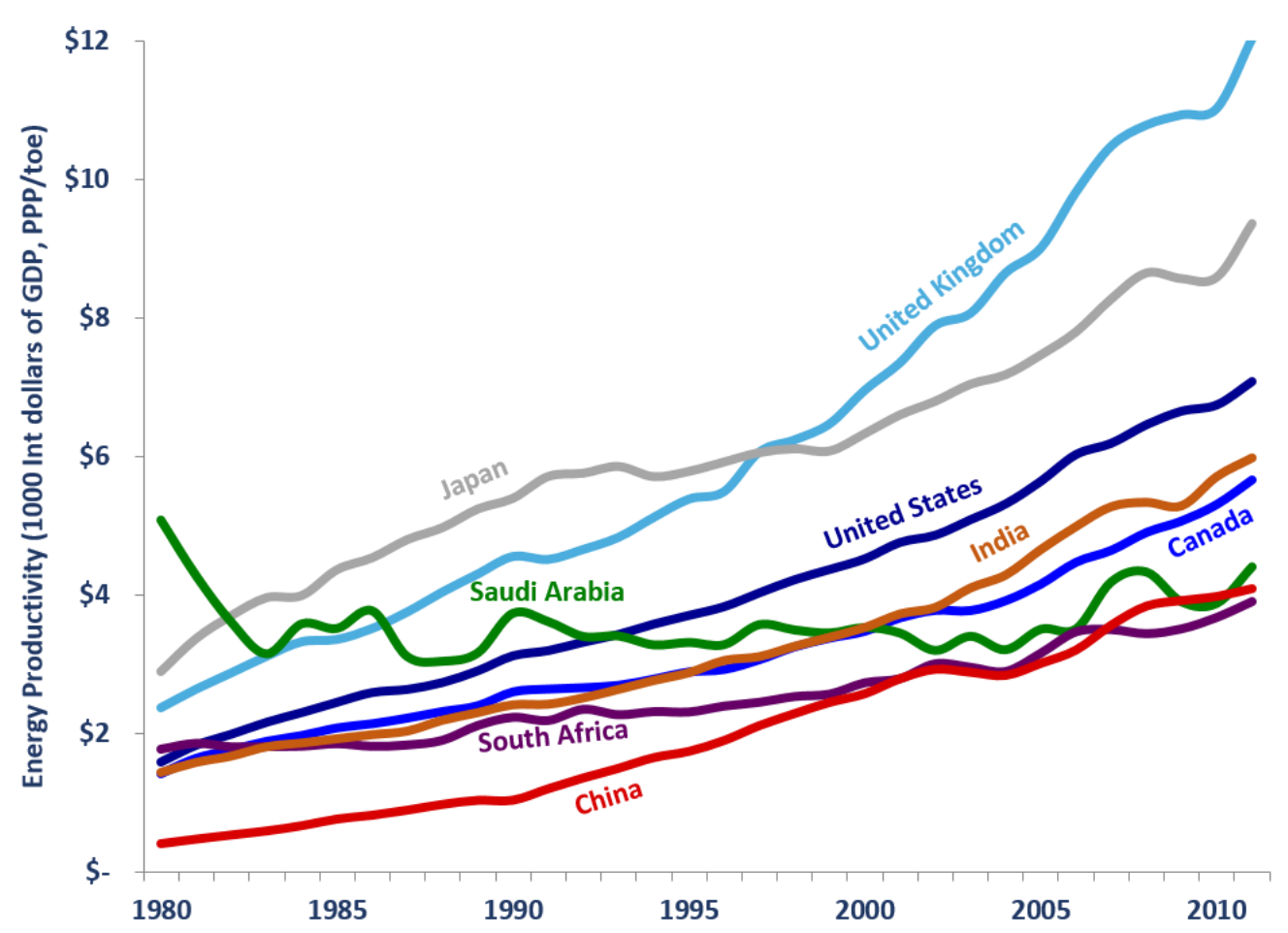

Figure 4: Changes in energy productivity for the same countries in Figure 3.2, 1980-2011. Same data source as above. 


\begin{tabular}{|c|c|c|c|c|c|c|c|c|}
\hline \multirow[b]{2}{*}{ Country } & \multicolumn{4}{|c|}{$\begin{array}{c}\text { Energy Intensity } \\
\text { (toe/thousand Int dollars of GDP, PPP) }\end{array}$} & \multicolumn{4}{|c|}{$\begin{array}{c}\text { Energy Productivity } \\
\text { (Int dollars of GDP, PPP/toe) }\end{array}$} \\
\hline & 1980 & 2011 & $\begin{array}{l}\text { Change } \\
1980-2011\end{array}$ & $\begin{array}{c}\text { Percent } \\
\text { Change } \\
1980-2011\end{array}$ & 1980 & 2011 & $\begin{array}{l}\text { Change } \\
1980-2011\end{array}$ & $\begin{array}{c}\text { Percent } \\
\text { Change } \\
1980-2011\end{array}$ \\
\hline China & 2.41 & 0.24 & -2.17 & $-90 \%$ & 410 & 4,160 & 3,750 & $915 \%$ \\
\hline India & 0.69 & 0.17 & -0.52 & $-75 \%$ & 1,450 & 5,990 & 4,540 & $313 \%$ \\
\hline Canada & 0.71 & 0.18 & -0.53 & $-75 \%$ & 1,410 & 5,670 & 4,260 & $302 \%$ \\
\hline United States & 0.63 & 0.14 & -0.49 & $-78 \%$ & 1,590 & 7,090 & 5,500 & $346 \%$ \\
\hline South Africa & 0.56 & 0.26 & -0.30 & $-54 \%$ & 1,780 & 3,910 & 2,130 & $120 \%$ \\
\hline UK & 0.42 & 0.08 & -0.34 & $-81 \%$ & 2,370 & 12,040 & 9,670 & $408 \%$ \\
\hline Japan & 0.35 & 0.11 & -0.24 & $-69 \%$ & 2,890 & 9,370 & 6,480 & $224 \%$ \\
\hline Saudi Arabia & 0.20 & 0.23 & 0.03 & $15 \%$ & 5,090 & 4,410 & -680 & $-13 \%$ \\
\hline
\end{tabular}

Table 2: Changes in energy intensity and energy productivity from $1980-2011$ for select countries.

\section{Portrayal of grander ambition}

Intensity and productivity targets are typically set relative to some base year. For example, in 2009, Sweden adopted a national target of cutting energy intensity by 20 percent by 2020 . The amplified dynamics of energy productivity targets can give them broader appeal with policymakers and the public, not only because they are framed as positive actions, but also because such targets appear more ambitious than the equivalent intensity target. For example, a goal of reducing energy intensity by 50 percent can instead be framed as a doubling or a 100 percent increase in energy productivity.

If Sweden had framed their 2009 energy goal in productivity terms, they would have been promoting a larger increase in energy productivity than the 20 percent decrease in energy intensity. Behavioral economics research has shown that more ambitious targets are perceived more favorably when setting goals relative to a reference point.

\section{Decaying to the mean}

The mathematical representation of the indicators also affects the perception of relative change over time when comparing performance between economies. Over the past thirty years nations have mostly seen their energy intensities decrease because of increasing GDP, lower energy consumption, or a combination of both. GDP is generally increasing faster than changes in energy consumption, and since GDP is the denominator in energy intensity, changes over time exhibit a pattern of decay. Over time the changes become infinitesimal compared to the base year, and countries appear to stabilize to the same fixed, tangent energy intensity level (Figure 3).

\section{Decaying to the mean gives rise to the energy intensity illusion}

Because of this pattern of decay, developed nations appear to lag developing nations in efforts to reduce their energy intensity. For example, between 1980 and 2011, China's energy intensity fell 90 percent, from 2.41 to 0.24 toe/thousand dollars (international, PPP), while Japan's fell 71 percent, from 0.35 to 0.11 toe/thousand dollars (international, PPP). Although China's decrease was larger on a percentage basis and in absolute terms than Japan's, by some measures Japan actually delivered a greater 
societal benefit because of something we call the energy intensity illusion.

\section{The energy intensity illusion}

By converting the same data into energy productivity terms, we find that although China's improvements in percentage terms (915\%) were larger than Japan's (224\%), Japan actually made a larger improvement in absolute terms $(\$ 6480 /$ toe $)$ than China's $(\$ 3750$ / toe). The differences in relative performance between nations becomes clearer when the same data from Figure 3 are plotted as energy productivity (Figure 4), and when the energy intensity and productivity changes are presented side-by-side (Table 2 and Figure 4, and note the widening gap between the two countries). The aim of this exercise is not to diminish the impressive improvements that countries like China have made, but rather to show that the gaps in performance between countries are larger than energy intensity values might suggest, leaving more room to create additional value from energy usage to the benefit of society.

The illusion occurs because energy intensity is a ratio, and therefore has a curvilinear relationship with its reciprocal, energy productivity. Countries with a high relative energy intensity (such as China, Saudi Arabia, and South Africa) have a relatively low energy productivity. Large energy intensity reductions in these countries, therefore, may only translate into small energy productivity improvements (Figure 5). By contrast, for countries characterized by lower energy intensity - and thus higher energy productivity - such as Japan and the UK, a small energy intensity reduction translates into large energy productivity gains (Figure 5).

\section{Energy productivity represents maximizing value creation from resource consumption, as opposed to minimizing resource use per unit of output}

Larrick and Soll identified a similar illusion in 2008 when comparing changes in motor vehicle fuel efficiency in terms of miles per gallon (MPG) versus gallons per mile (GPM). The perception is that a change from $15 \mathrm{MPG}$ to $16 \mathrm{MPG}$ results in equivalent fuel savings as improving fuel efficiency from $35 \mathrm{MPG}$ to $36 \mathrm{MPG}$. This perception is incorrect because of the same curvilinear properties seen in energy productivity and intensity. An
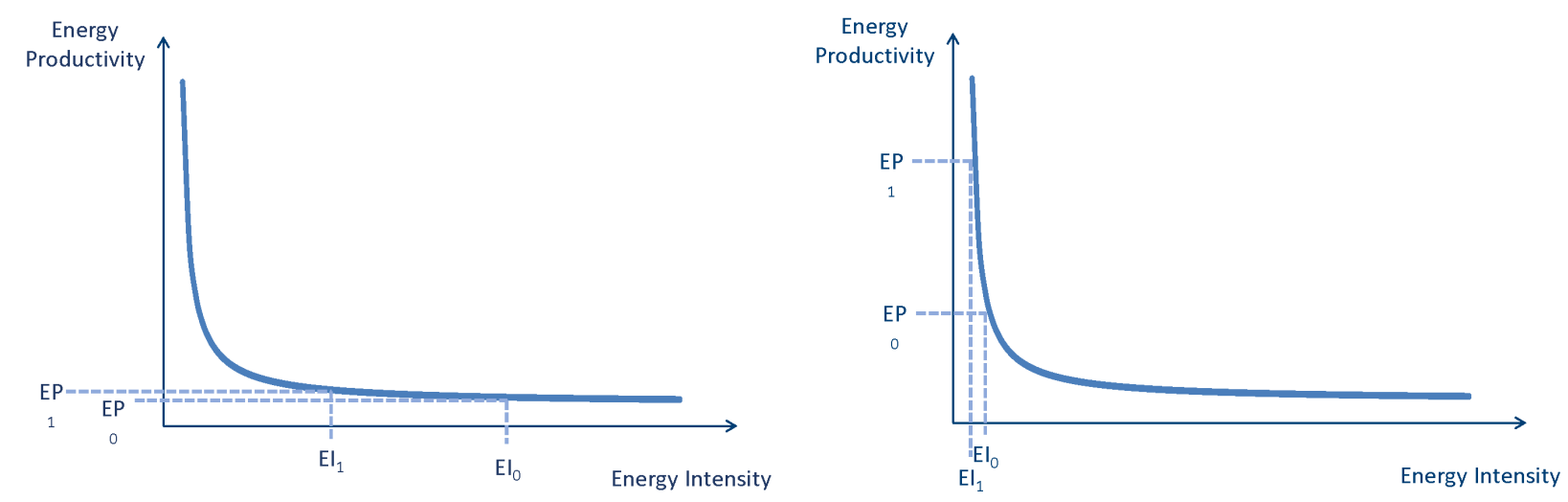

Figure 5: Left: Large reductions ( $E l_{0}$ to $\left.E l_{1}\right)$ in energy intensive countries translate into small energy productivity gains $\left(E P_{0}\right.$ to $\left.E P_{1}\right)$. Right: In countries with low energy intensities, small intensity reductions $\left(E l_{0}\right.$ to $\left.E l_{1}\right)$ translate into large energy productivity improvements $\left(E P_{0}\right.$ to $\left.E P_{1}\right)$. 
efficiency improvement of 15 MPG to $16 \mathrm{MPG}$ actually yields over five times more fuel savings than going from $35 \mathrm{MPG}$ to $36 \mathrm{MPG}$.

The authors argued that using GPM to measure vehicle fuel efficiency is more indicative of the amount of fuel saved when making a motor vehicle efficiency improvement. By the same measure, energy productivity is a more directly relevant measure of a country's economy, energy, and environmental performance because it represents maximizing value creation from resource consumption, as opposed to minimizing resource use per unit of output. While the former is a noble goal from the point of view of conservation, the latter is actually the more worthwhile objective, as it contributes directly to increasing societal benefits and human welfare with the least amount of energy expenditure.

\section{Conclusions}

A variety of indicators, targets, and policy options are available to policymakers to help manage economic competitiveness, energy security, and environmental quality issues. Policymakers have an opportunity to enroll greater public support by focusing on energy productivity rather than energy intensity.

Although the differences between energy productivity and energy intensity may seem inconsequential on the surface, the implications are not. The two indicators are more than just reciprocals of one another. Energy productivity conveys a more positive message, aligning it more closely with principles of behavioral economics including cognitive framing and bounded rationality. It is expressed in monetary terms, making it more intuitive to a wider audience. Furthermore, the mathematical representation of energy productivity can provide additional insights into the relative performance of nations over time and actually enhance the framing of policies.

Nations have seen the value of building consensus around intensity measures, but have overlooked the potential benefits that a productivity prospective provides. Ultimately, energy productivity can be a useful indicator for measuring economic, energy, and environmental performance, or for creating policy targets in all countries, regardless of whether they have existing intensity-based programs or not.

\section{References}

ABB. 2013. Global Trends in Energy Efficiency: Country Reports.

Dellink, R. 2010. Cost Effectiveness of the Copenhagen Pledges: Assessing global greenhouse gas emissions targets and actions for 2020. OECD.

Dobbs, R.; Oppenheim, J.; Thompson, F.; Brinkman, M.; Zornes, M. 2011. Resource Revolution: Meeting the World's Energy, Materials, Food, and Water Needs. McKinsey Global Institute.

Duchan, D.; Dunegan, K.J.; Barton, S.L. 1989. Framing the problem and making decisions: the facts are not enough. IEEE Transactions on Engineering Management.

Houde, S.; Todd, A. 2011. List of Behavioral Economics Principles that can Inform Energy Policy. Lawrence Berkeley National Lab and Precourt Energy Efficiency Center at Stanford University.

IEA. 2012. CO2 Emissions from Fuel Combustion. International Energy Agency.

Larrick, R.P.; Soll, J.B. 2008. The MPG illusion. Science, 320, 1593-1594. 
Levin, I. P.; Gaeth, G.J. 1988. How consumers are affected by the framing of attribute information before and after consuming the product. Journal of Consumer Research. 15: 374-378.

Lewis, J. 2011. Energy and Climate Goals of China's 12th Five-Year Plan. Center for Climate and Energy Solutions.

Pizer, W. 2005. The Case for Intensity Targets. Resources for the Future, discussion paper 05-02.

Sher, S.; McKenzie, C.R.M. 2008. Framing effects and rationality. In $\mathrm{N}$. Chater and $\mathrm{M}$. Oaksford
(Eds.), The probabilistic mind: Prospects for Bayesian cognitive science. (pp. 79-96). Oxford: Oxford University Press.

Swedish Parliament (Riksdag). 2011. Sweden's Second National Energy Efficiency Action Plan.

UNF: Expert Group on Energy Efficiency. 2007. Realizing the Potential of Energy Efficiency: Targets, Policies, and Measures for the G8 Countries. United Nations Foundation, Washington, DC. 


\section{About the author}

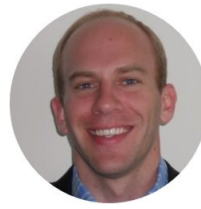

Patrick Bean is a Research Associate examining the determinants of energy productivity changes and performance. Prior to joining KAPSARC, Patrick was a senior energy policy advisor at the American Clean Skies Foundation, and a strategic generation planner at one of the United States' largest electric utilities, Southern Company. He has authored a variety of papers on energy and environmental topics, including electricity planning and natural gas markets. Patrick has a M.E.M. degree in energy and environmental resources from Duke University, and a B.S. degree from Marist College.

\section{About the Energy Productivity Team}

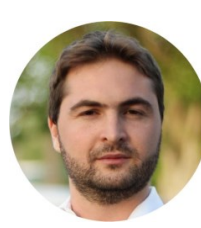

Tarek Atallah is a Senior Research Analyst evaluating energy productivity investments and the effect of climate on energy consumption patterns. $\mathrm{He}$ is currently a Ph.D. candidate.

Berenice Garcia-Tellez is a Senior



Research Analyst evaluating embodied energy in trade, and researching the energy-water nexus. She has a M.S. degree from KAUST.

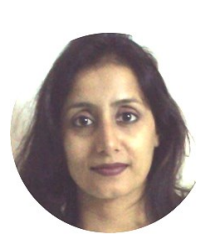

Kankana Dubey is a Research Associate investigating patterns of energy consumption in the water supply chain. She holds a M.S. degree from the University of Stirling.

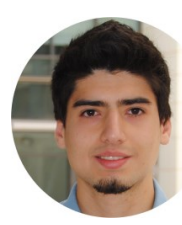

Anwar Gasim is a Senior Research Analyst examining embodied energy flows in international trade, and energy productivity investments. He holds a M.S. degree from KAUST.

Sadeem Al-Hosain is a Data Analyst investigating global flows of embodied energy in trade. She has a M.S. degree in E-Business Systems from City University London.

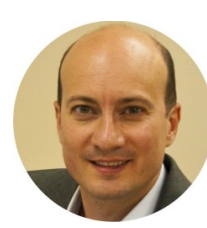

Nicholas Howarth is a Research Fellow coordinating KAPSARC's Energy Productivity research, especially global investment. He holds a Ph.D. degree from Oxford University.

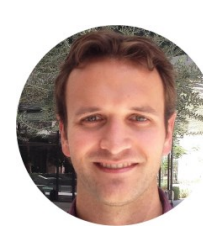

Christopher Napoli is a Senior Research Associate investigating embodied energy in international trade. He holds a Ph.D. degree from the University of Kent.

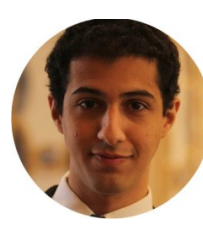

Yazeed Al-Rashed is examining how various factors influence energy productivity changes. He has a M.S. degree from Columbia University and a B.S. degree from MIT. 